\title{
Effects of light stimulus upon simple reaction time and EP latency to the click presented with different SOA $^{1}$
}

\author{
SHUNJI MIYAKE, SHUNJI TANIGUGHI and KEIIGHIRO TSUJI

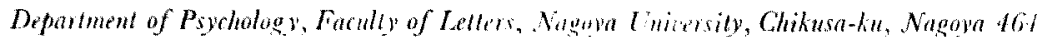

\begin{abstract}
Click and light were presented in pairs with varying stimulus onset asynchronies (SOAs) and the subjects were asked to respond to the click onset. SRTs and EPs were obtained for two levels of click intensity and were plotted as a function of SOAs. As the related EP component, Nc, or the negative peak immediately following the click onset, was taken and the $\mathrm{Nc}$ recorded from $\mathrm{C} z$ was analyzed. Although the larger $\mathrm{Nc}$ amplitudes occurred with shorter SRTs, no systematic changes in Nc amplitude were observed as a function of SOAs. Ne latencies, the variations of which were smaller for an intense click than for a faint one, were shorter for trials in which light preceded click (SOA $\leqq 0$ ) than for click-alone trials, in correlation with SRTs. This fact suggests that the light given prior to click increased the arousal level and/or the processing speed. Bimodal facilitating effect of the internal processing speed upon SRTs was obtained at $50 \mathrm{~ms}$ of $\mathrm{SOA}$.
\end{abstract}

Key words: evoked potentials (EPs), simple reaction time (SRT), stimulus onset asynchrony (SOA), bimodal stimulation, latency, facilitation.

Intensity of imperative stimulus and the foreperiod have been known as variables affecting simple reaction times (SRTs). The former (Nissen, 1977) is assumed to have a direct relation to stimulus processing in the sensory pathways as such. The latter (Niemi \& Näätanen, 1981), i.e., onset interval between signal and imperative stimuli seems to influence non-specific activating processes. Thus these two are possibly involved in different functions, although the processes underlying them have not been identified so far.

To relate the effects of these two variables to each other, the present study manipulates both variables by presenting light and click bimodally and obtains both SRTs and evoked potentials (EPs) in a single paradigm.

EPs could be a promising measure to clarify the processes underlying SRTs. Some investigators have obtained relationships between EP amplitudes and SRTs.

1 Data in the present article were partly reported at the 47th Annual Convention of the Japanese Psychological Association. Requests for reprints should be addressed to Shunji Miyake.
Donchin and Lindsley (1966) reported that the shorter SRTs were correlated with the higher amplitudes of EPs. Morrell and Morrell (1966) found that intra-individual variability of SRTs was related to that of VEP (visually evoked potential) amplitudes of the predominant component. Morris (1971) demonstrated a relation between increased amplitudes of VEPs (N2, P2) and the faster SRTs. Furthermore, Karlin, Martz, Brauth, and Mordkof (1971) obtained a similar relationship between SRTs and AEP (auditory evoked potential) amplitudes. These findings could be based on arousal or alertness which is activated by the non-specific projecting system of the ascending reticular formation.

There have been reported some studies which related SRTs to latencies of early EP components. This type of correlation was obtained in relation to light intensity (Dustman \& Beck, 1965; Vaughan, Costa, \& Gilden, 1966), retinal eccentricities of stimulation (Eason, Oden, \& White, 1967), and spatial frequencies (Parker \& Salzen, 1982). These could be determined by speed of the sensory processing.

In general, investigators who are con- 
cerned with relations of EP amplitudes upon SRTs have paid more attention on the activating function of sensory inputs, while those who relate EP latencies to SRTs are more concerned with speed of processing in sensory pathways. No studies have been reported which obtained these wo EP measures in a single paradigm. The present study attempts to compare them.

In the experiment, click (SI) and light (S2) are presented in pairs with varying onset asynchronies (SOAs), and subjects are asked to respond to the click. It is probable that light elicits arousal or attention for $\mathrm{SO} .1<0$ where $\mathrm{S} 2$ precedes $\mathrm{SI}$ but that light causes no such effects for $S O A \geqq$ 0. Click intensities are also set at two lovels, as they are expected to determine the speed if processing.

Bimodal facilitating effect upon SRTs has been demonstrated (Andreasis \& Greco, 1975; Bernstein, Rose, \& Ashe, 1970; Bernstein, Chu, Briggs, \& Schurman, 1973; Hershenson, 1962; Hilgard, 1933; Morrell, 1967; Nickerson, 1973). When light and click were paired at an optimal intensity and with proper time relation, SRTs were shorter than those obtained for each of them singly. In the present study, EPs can be related to reductions in SRTs, il the facilitation occurs.

EPs from $\mathrm{Cz}$ are analyzed because this area produces auditory potentials and also it has a clase relationship 10 motor responses.

\section{Method}

\section{Subject}

Subjects were four male university students. Their visual and auditory acuities were normal. All of them had experiences with SRT experiments.

\section{Stimuli}

As shown in Fig. 1, click and light were presented in pairs of eight SOAs; -200 ,
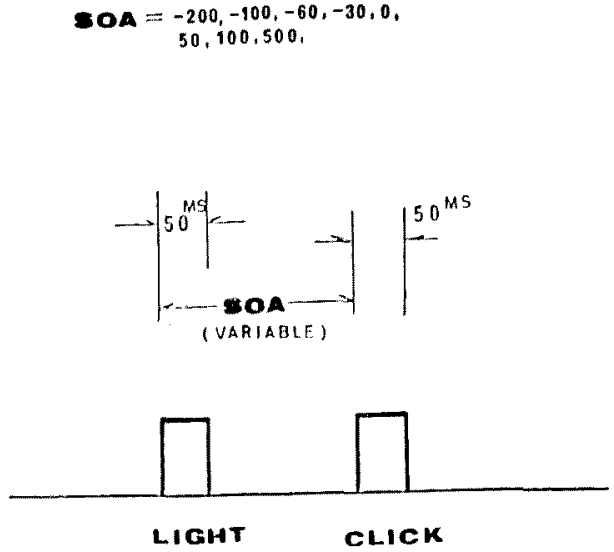

Fig. 1. Time sequence of the stimuli used in the experiment.

$-100,-60,-30,0,50,100,500 \mathrm{~ms}$.

Glick $^{2}$ was a pure tone of $1000 \mathrm{~Hz}$. It was presented for $50 \mathrm{~ms}$ at either of two levels, intense $(94 \mathrm{~dB})$ and faint $(74 \mathrm{~dB})^{3}$. The intense click was perceived as fairly loud, while the faint one was slightly above threshold and just audible. To mask external cues, background white noise (69 $\mathrm{dB})$ was given. Click and the white noise were presented binaurally through headphones.

Light was a disc of $2^{\circ}$ in visual angle and was exposed at the intensity of $28 \mathrm{~cd} / \mathrm{m}^{2}$ for $50 \mathrm{~ms}$.

\section{Instrument and Apparalus}

Stimulus presenting system. Figure 2 shows diagram of instrumentation. Timer 1 controlled the duration of click and triggered digital timer (National Electric Counter, VP-454A) which was used for SRT measurements. Timer 2 operated SOAs. Timer 3 controlled duration of light, triggering a pulse to onset light.

2 The auditory stimuli in the present study may be better described as the tone burst. We conventionally call it click in relation to the related studies cited in the introduction.

${ }^{3}$ Click intensity levels were measured by a microphone of an audiometer attached to the headphone lirectly. 
Click was generated by an oscillator (Nippon-Keisoku Audio Oscillator, M.D., CR-223AS). White noise was given through a tape deck (Teac, ff-80). Both of them were delivered through headphones (Pioneer SE-30) after being mixed by sound mixer (Teac, MB-20). Light was projected on a white screen through diaphragm inserted in the optical path by a projector (Kodak Ectagraphic Slide Projector) with DC power supply (Sanso Power Supply, KD-300). An electromagnetic shutter (Sanwa Shutter Driver) controlled duration of light.

Recording system. EEGs were recorded monopolarly. Active electrodes were placed at $\mathrm{Cz}, \mathrm{Pz}$ and $\mathrm{O} z$ in 10-20 system while a reference electrode was on the right earlobe. As shown in Fig. 2, EEGs were amplified with a band pass of $0.53-30 \mathrm{~Hz}$ and were stored in the data recorder (Sony, FF-30a) together with trigger signals. They were processed later by a signal processor (San'ei, 7T08) to obtain EPs which were plotted on X-Y recorter (San'ei, 8U11).

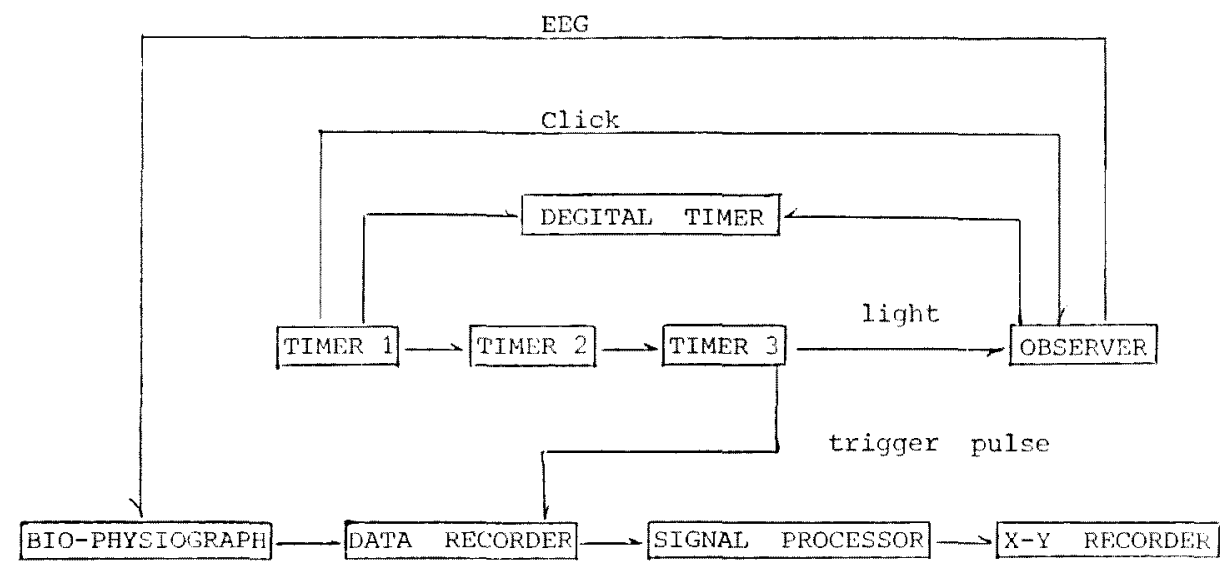

Fig. 2. Diagram of the apparatus system.
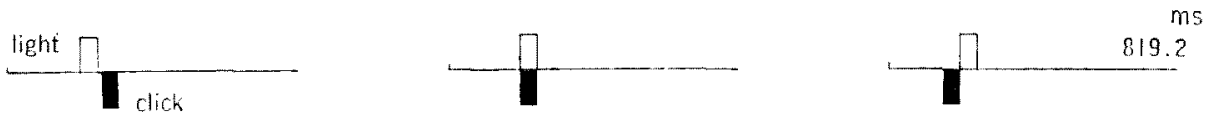

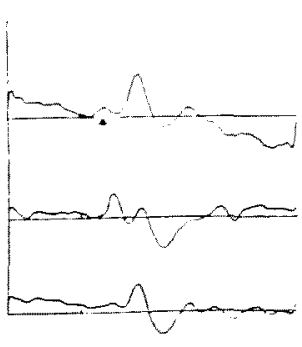

SOA -60

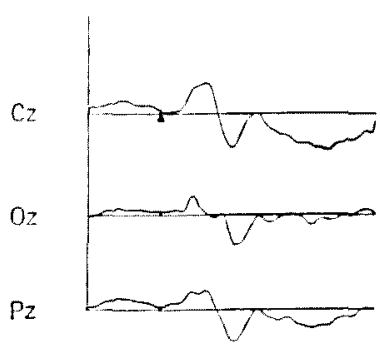

SOA 0

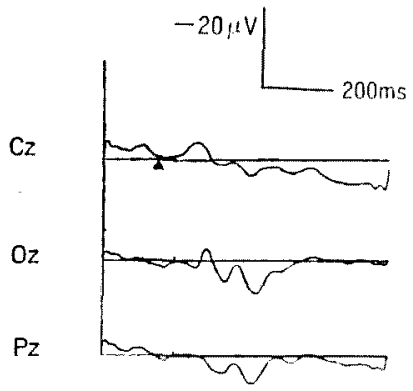

SOA 50

Fig. 3. Evoked potentials for faint click recorded from $\mathrm{Cz}, \mathrm{O} z$ and $\mathrm{P} z$. From left to right, data are arranged for the SOAs of $-60,0,50 \mathrm{~ms}$. Onset of light is indicated by short vertical line and click onset is marked by triangle. Sweep lime is $819.2 \mathrm{~ms}$. Data fiom subject KO. 
Each EP was averaged by summing 40 trials and recorded with sweeping time of $819.2 \mathrm{~ms}$ (1 $024 \mathrm{~ms}$ only for SOA of 500 ms.)

EEGs were monitored with a biophysiograph (San'ei Polygraph, 141-6) while they were recorded. EOG was also recorded to detect eyeblinks and the trials in which an eyeblink occurred were discarded from analysis.

\section{Procedure}

A subject, sitting in a dimly illuminated room, was asked to press a response key as soon as he heard click against the background white noise. A session consisted of ten conditions, i.e., eight SOAs plus single presentations of light and click. For each condition SRT trials were run at least 40 times with 4-s interval. A 3-min rest was given between conditions, and 5 -

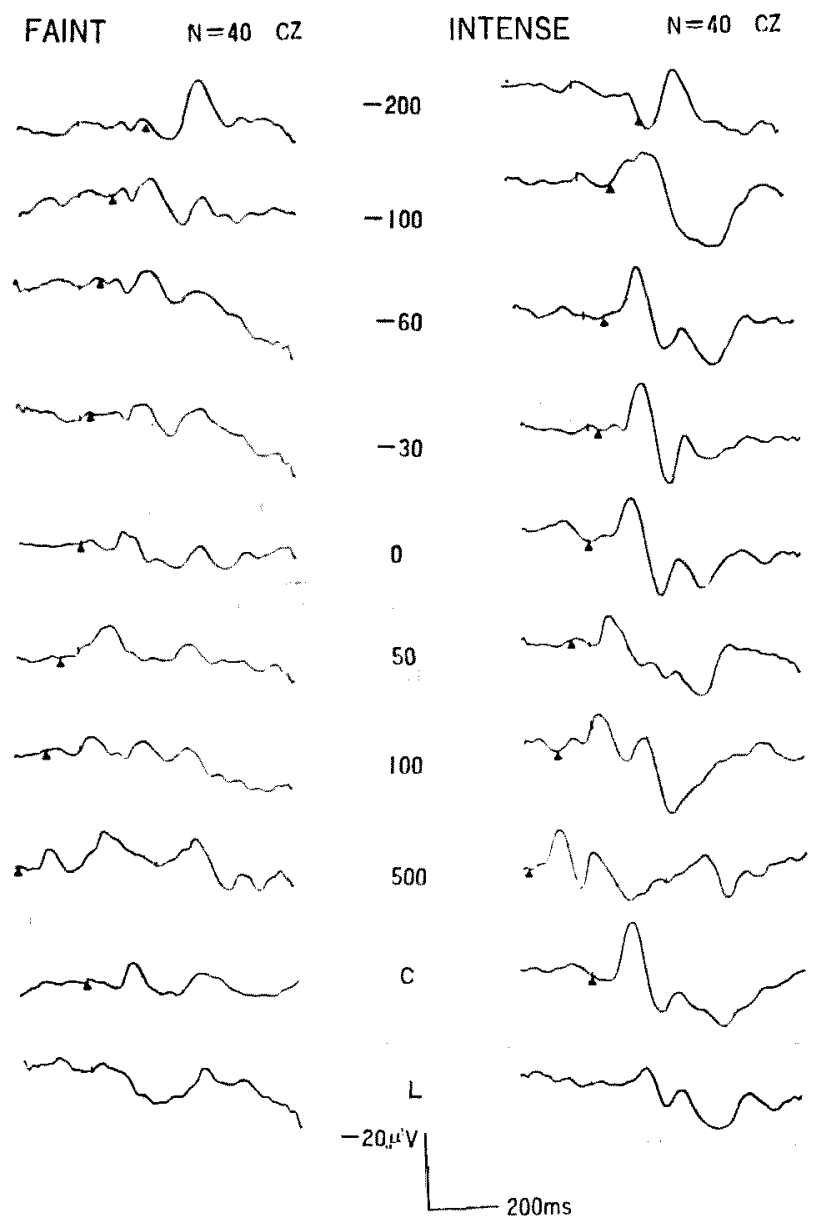

Fig. 4. Evoked potentials for each condition of faint click (left) and intense click (right) recorded from $\mathrm{C}$. . C indicates the click alone condition, and $\mathrm{L}$ indicates the light alone condition. Trigger point (onset of light) is indicated by short vertical line, and click onset is marked by small triangle on each trace. Sweep time is $819.2 \mathrm{~ms}$ except for the SOA of $500 \mathrm{~ms}$. 
min interval was inserted after crov three conditions.

Each subject was given both intense and laint click sessions. The order of conclitions and of sessions were both raudomized.

\section{Analysis of LP Data}

ligure 3 illustrates the LP thates acorded from diflerent arcas ( $(\mathrm{b}, \mathrm{P} \%, \mathrm{O})$ and for different SOAs $(-60,0,50 \mathrm{~ms})$. In the ligure, the click onset is indicated by a solid triangle and the light onset (trigger point) by a vertical linc.

Is a response croked by click, a large negative component was identificel immediatcly after onset of the click. It was nancd Xic. Both latency and amplitude of the $\mathrm{ie}$ component recorded from (iz were measured in order to correlate with Sk'l.

Result

\section{LP Mensues}

Amplitudes of . To component. ligure \& illustrates EPs obtaincl from a subject (MI) for laint click (left) and lor intense click (right). Intens click evoked larger No amplitudes at each $\mathrm{SOA}$ than faint click did.

ligure 5 compares mean Nc amplitudes and mcan SRTs plotted against SOAs in both click intensities. Within the same SOA, larger amplitudes occurred with shorter SRTs, and the tendency seemed consistent within subject. However, no systcmatic change in $\mathrm{N}_{\mathrm{c}}$ amplitudes was observed when the amplitudes were plotted against SOAs.

Lalencies of No component. Figurc 6 shows Ne latencies plotted against SOAs for both click intensitics.

For faint click, latency decreased over $-2(10-100 \mathrm{~ms}$ of $\mathrm{SOA}$, then increased. At 50 mis of SOA, it reached the same level as obtaincd in click alone condition, and was kept at constant value of approximatcly 140 ms after that S( $)$.

Latencics for intense click were shorter than those for a faint one except - $100 \mathrm{~ms}$ of $S() .1$. Though their variation was remarkably smaller when compared with those lor faint click, the differences among SOAs wcre still significant $(F(8 / 54)=5.81$, $p<.01)$.

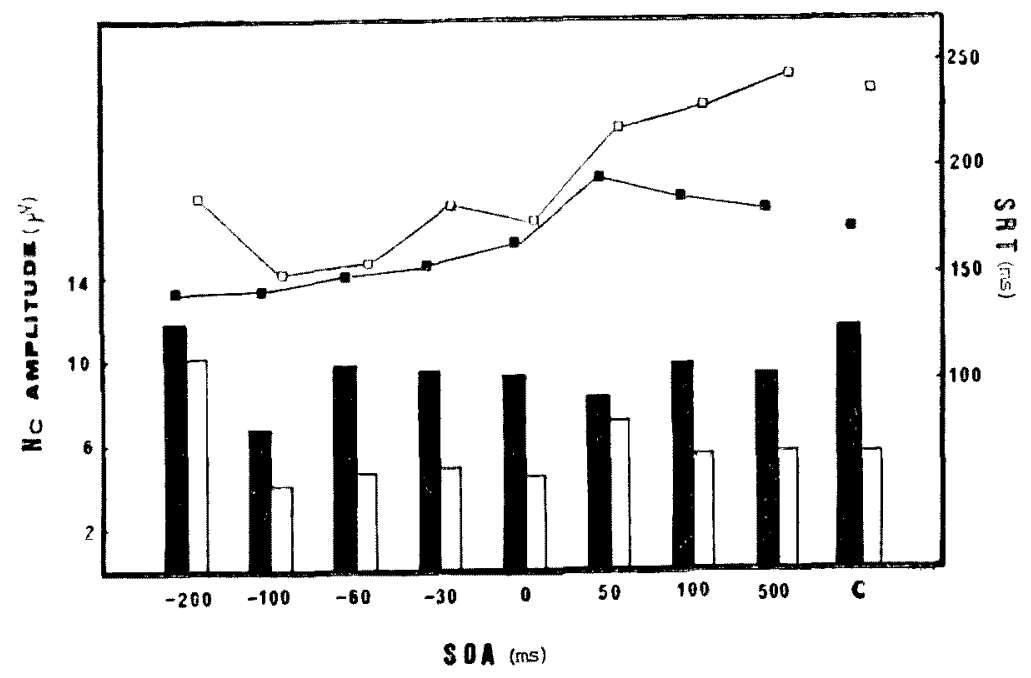

Fig. 5. Nc amplitudes for each SOA condition for faint click (white bars) and for intense click (black bars). SRTs to click plotted against SOAs for faint click (open squares) and for intense click (solid squares). 
Comparcel with click alone, these latencies were significantly reduced over -100 $(l(3)-5.91, p<.001)-0$ mis $(l(3)=2.45, p<$ $.05)$ of SO.1. Though the difference betwcen click intensities was also significant
$(F(1 / 54)=37.4, p<.001)$, the two SOA functions were similar to cach other in that both bottomed at $-100 \mathrm{~ms}$ of SOA and reached the click alone level at $50 \mathrm{~ms}$ ol SOA.

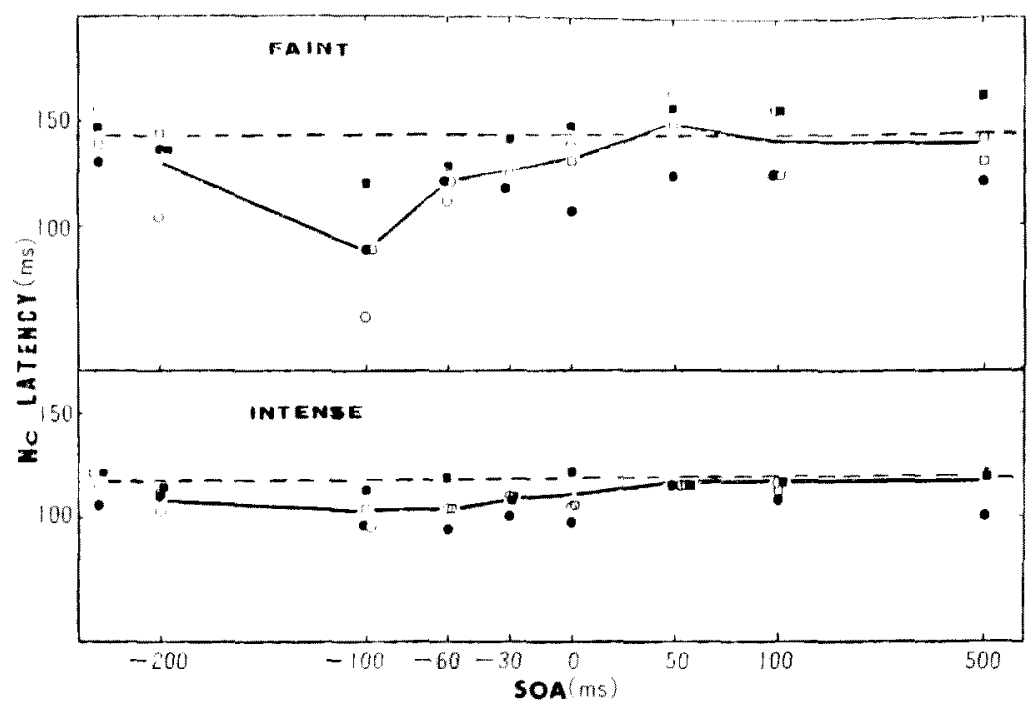

1.5. 1. Latem ies of Ne ampoment plotted agaims so hs for faint alick (upper) and fur intense click (lower). Dhe indie ale lathe ics obtained from individual subjects, and selid line shows mean hatencies.

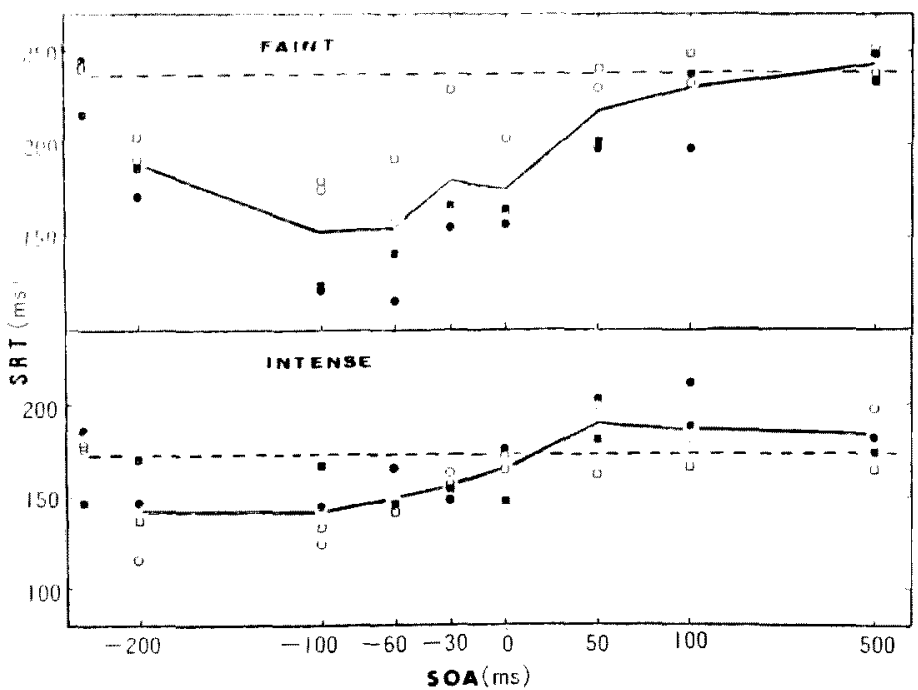

Fig. 7. SRTs to click plotted against SOAs for faint click (upper) and for intense click (lower). Dots indicate SRTs obtained from individual subjects, and solid line shows mean SRTs. 


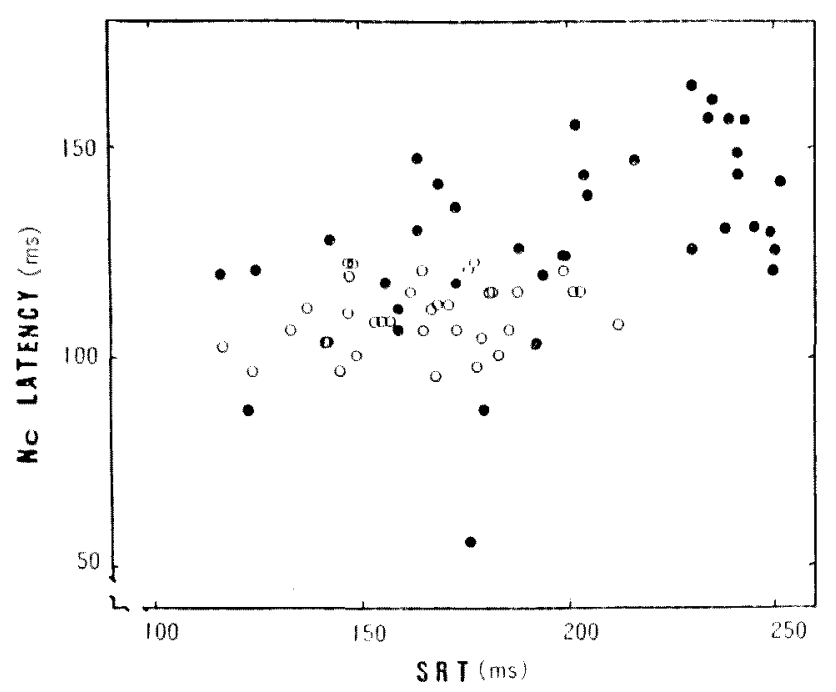

Fig. 8. Latcnics of No component plotted agaitst SRTs. Open circles indicate the data obtained for intense click, while solid circles for faint click.

\section{SRT Marure}

Figure 7 giscs SRI's plotted ayainst SOAs for both click intensities. Difference in SRTs between the two click intensities was significant $(F(1 / 60)=36.8, p<.001)$.

SRTs to faint click decreased over $-200-100 \mathrm{~ms}$ of SOA, then increased and reached the level for click alone $(236.3 \mathrm{~ms})$ at 100 or $500 \mathrm{~ms}$ of SOA. SRTs to intense click also increased slightly for $-200-50 \mathrm{~ms}$ of SOA, reaching the level for click alone (172.1 ms), and kept constant level after that. SRT variations among SOAs were significant $(F(9 / 60)=$ $11.93, p<.01)$.

Amount of time reduction from the click alone level was significant only for the $\mathrm{SOA}$ rangc $-60 \quad(t(3)=2.68, p<.05)-0$ ms $(l(3)=2.49, p<.05)$ of intense click condition.

Bimodal facilitations were seen for both click intensities; over $-200-50 \mathrm{~ms}$ of SOA for faint click and over $-60-0 \mathrm{~ms}$ for intense click.

SRT to faint click alone (236.2 ms) was significantly longer than SRT to light alone (177.9 ms) (l(3)-6.61, $p<.001)$, while SRT to intense click alone (172.1 ms) was significantly shorter than that to light alone $(201.8 \mathrm{~ms}) \quad(l(3)=5.66, p<.01)$. And, consequently, the diflerence in SRTs between both click alone conditions was significant $(l(3)=28.5, p<.001)$, which is congruent with the findings reviewed by other investigators (Nissen, 1977; Teichner, 1954).

\section{Relation between SRT and LP Mcasures}

Figure 8 show's relationship between SRTs and Nc latencies. It was obtaincd with data for eight SOAs plus click alone from four subjects. Coefficient of correlation was .579 and statistically significant

4 Two SRTs to light should be the same since light intensity was physically the same for both click conditions. But, as a fact, they clitfercd. SRT to light alone was shorter by $23.9 \mathrm{~ms}$ in the faint click condition than in the intense click condition $(t(3)=3.25, p<.05)$. The difference could be attributed to the fact that light appeared more impressive and flashy in the faint click condition owing to the sequential context produced by the bimodal stimulation. 


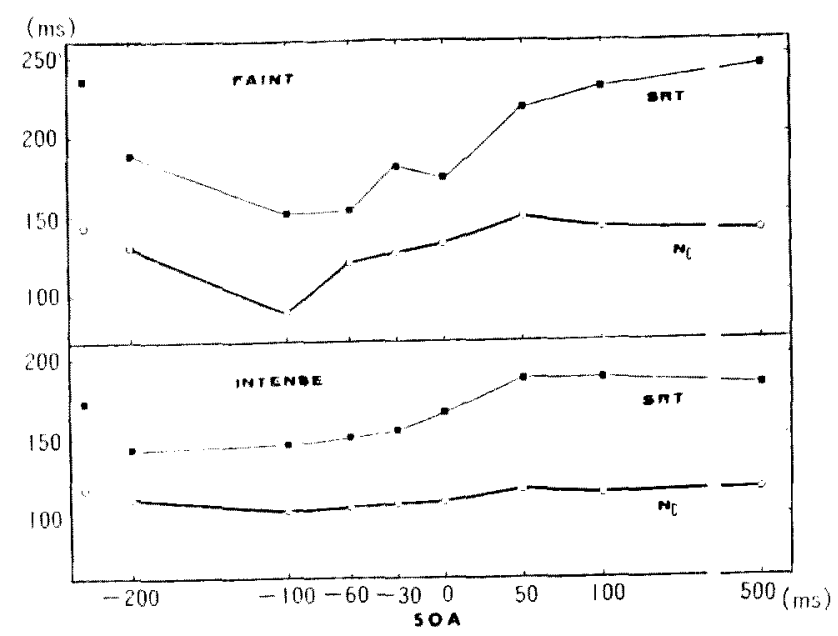

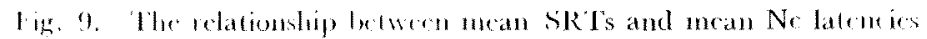
lor linte dick (upper) and lor intense tlick (lower). Duth are plutted as it function of SOSA.

$(1(71)-, 3.97, p<.001)$

()in the other hand, Ne amplitudes showed no significant coeflicicnt of correlation with SRTs (cocfficient of correlation was $-.096, l(70)=.81$,, r. $)$, though intense click tended to produce larger amplitudes than laint me did.

Figure 9 gives mean SR'l's and mean Ne latencies ploted as a function of $\mathrm{SO} . \mathrm{As}$ for the two click intensities. These two changed parallelly as a whole, though $S R$ 's reached the click alone level at 100 or $500 \mathrm{~ms}$, at later $\left.\$()_{\mathrm{A}}\right)$ than the latencics did.

\section{Discussion}

Our findings are related to those obtained by other investigators. Donchin and Lindsley (1966) demonstrated a relationship between SRTs and VEP amplituckes". In their cxperiment, amplitudes of the N 160-200 component were found to be larger when SRTs were shorter. In the

\footnotetext{
5 In this study the authors were mainly concerned with the effect of SRT given as a feedback information, not with the efrect of interstimulus intervals.
}

present study, larger $\mathrm{Nc}$ amplitudes and shorter SR'I's were obtained for intense click when compared with those for faint click (sce Fig. 5).

Vaughan et al. (1966) reported the relation between SRTs and VEP latencies. They changed the intensity of the imperative stimulus and observed that SRTs and latencies of the $P_{1}$ component varied correspondingly. In the present study, a significant correlation was found between SR'I's and Ne latencies when those were measured at different SOAs.

Similarity of the findings between the study by Vaughan et al. and ours is worth noting because the similar effects were demonstrated by operating different paramcters, i.e., the stimulus intensity level and the prestimulus time condition. This suggests that time and intensity have interchangeable effects upon internal processes underlying motor responses.

$\Lambda$ well known fact is that a signal stimulus with foreperiods can reduce SRTs. Foreperiods in Donchin and Lindsley (1966) ranged from 1.0 to $2.5 \mathrm{~s}$, while SOAs in the present study were from -200 to $500 \mathrm{~ms}$. SRTs varied with EP amplitudes in the former study, while with EP 
latencies in the present study. The dilferent SRT-related EP measures between the wo studies suggest that longer loreperiods may increase the arousal or alertness level which reduces the stimulus processing time at one processing stage and that shorter SO.Is may save processing at a different, and carlier stage.

For faint click, SRT's for $-200-50 \mathrm{~ms}$ and Nc latencies for $-100-0 \mathrm{~ms}$ of $\mathrm{SOA}$ were shorter than those in click alone. For intense click, only SRTs were reduced for $-60-0 \mathrm{~ms}$ of SO. 1 . Amount of these reductions was smaller for intense click than for the faint one. The difference in the amounts may be attributed, among all, to the intensity level relative to light. The two clicks differed not only in their absolute level but also in the subjective level relative to light. Secondly, the difference may be caused by a cciling eflect; both measures for intense click may have reached the level not capable of being accelerated by light any more, Intensities of light and click should be systematically varied in order to specily the crucial variable.

Another diflerence in the SOA function between two intensity levels of click was that the SRT reduction for $50 \mathrm{~ms}$ SOA was obtained only for laint click. SR'T to laint click at $50 \mathrm{~ms} \mathrm{SO}$ was shorter than that to the click alone, although the difference failed to reach a conventional significance level $(l(3)=1.85, p<.1)$. This SOA was approximatcly cqual to the SRT difference between the click alone and the light alone conditions $(58.3 \mathrm{~ms})^{6}$. Thus the subjects would perceive both stimuli as presented simultaneously if the motor system functioned with equal speed in both cases, This is a kind of facilitating effect of intersensory stimulation upon SRT's, as

\footnotetext{
6 In the intense click condition, SRT for the click alone was shorter than the light alone by $29.7 \mathrm{~ms}$. Therefore click and light would have reached central nervous system at approximately same time for SOA of $-30 \mathrm{~ms}$. In fact, SRT was reduced in this $\mathrm{SOA}$ condition.
}

repented by some investigators (Bernstein it al., 1970, 1973; Helson, 1964; Hershenson, 1962; Morrcll, 1967; Nickerson, 1973). Andreassi and Greco (1975) demonstrated reduction in SRT's to light and the amplitude augmentation of N2 component which occurred in the bimodal stimulation. They obtained this effect by presenting two stimuli with delay cqual on the time difierence in SRT ( $\Delta \mathrm{R}^{\prime} \mathrm{T}$ ) or N2 latency ( $J N 2)$. In the present study reduction appeared in SRT, but not in the Nc latency.

In the present study the Ne component was taken as the EP measure. $N_{c}$ is a distinct component which followed the click presentation. To make the clickrelated eflect clearer Nc from (iz was measurcd. However, it is questionable that any light-related component, say NI, might have been compounded with it, since the two evoked potentials actually occurred in a close temporal relation in our paradigm. It could be argued that a purcly click-rclated component could exist if the EP wave for light alone was subtracted from the EP wave in bimodal stimulation. However, the two stimuli interact to cause a unitary internal process which underlies motor responses in the bimodal stimulation with brief SOAs. This process may not be a linear summation of the light-elicited and the clickelicited processes. Although our vicw mentioned here should be tested in further studics, the high cocflicient (.579) of $\mathrm{Ne}$ latencies with SRT's already gives the partial support for it.

As is well known, SRTs and their variance depend upon the paradigm used in the experiment. In the present study, 40 trials werc run successively with 4-s interval for each condition. Our subjects, therefore, would tend to time the click onset more easily. One of them showed extraordinarily short SRT to faint click over $-100--60 \mathrm{~ms}$ of SOA. Such quick responding may be partly due to the paradigm with fixed interval. SOAs could be 
changed randomly trial after trial, and undoubtedly this is more desirable to cxclude the subject's preparatory set. 'Though we ran each series of 40 trials with identical SOA for technical reasons, further neasurements should be made by using a paradigm with random intervals.

\section{References}

Andrcasi, J. L., \& Gicco, J. R. 1975 Lilicats of biscusony stimulation on reaction time and the croked cortical evoked polential. Physiological Psychology, 3, 189-194.

Bemstein, I. H., Rose, R., \& Ashe, V. M. 1970 Lncrgy intogration in intersensory facilitation. Journal of Experimental Psychology, 86, 196-203.

Bernstein, I. H., Chu, P. K., Briggs, P., \& Schurman, D. L. 1973 Stimulus intensity and forcperiod cllects in intersensory facilitation. Quarter1y Journal of Experimenial Pschology, 25, 171-181.

Vonchin, E., \& Lindslcy, D. B. 1966 Average croked potentials and reaction lime to visual stimuli. Electroencephalography and Clinical Neuroplysiology, 20, 217-223.

Dustman, R. L., \& Beck, L. C. 1965 Phase of alpha brain wave, reaction linc and visually croked potentials. Electrencephalography and Clinical Nourophosiology, 18, 433-440.

lason, R. G., Odcn, D., \& White, C. 'T', 1967 $V$ isually evoked cortical potentials and reaction line in relation to site of retinal stimulation. Electroencephalography and Clinical Neurophysiology, $22,313-324$.

Ilckon, H. 1961 Cirrent uonds and issues in adaptation-lcvel theory, Lincrioan Pyychologist, 19, 26-38.

Hershenson, M. 1962 Reaction time as a matsure of intersensory facilitation. Journal of Ex- perimental Psychology, 63, 289293.

Hilgard, E. R, 1933 Reinforcement and inhibition of cyclid reflex. Journal of General Psychology, 8, 85-113.

Karlin, L., Mart $\iota$, M., Brauth, S. E., \& Mordkolf, A. M. 1971 Auditory evoked potentials, motor potcntials and reaction timc. Electroencephalography and Clinical Neurophysiology, 31, 129-136.

Morrell, L. K. 1967 Intersensory facilitation of reaction timc. Psychonomic Science, 23, 193-195.

Morrell, L. K., \& Morrell, I'. 1966 Evoked potentials and reaction time: A study of intra-individual variability. Electroencephalography and Clinical Neurophysiology, 20, 567-575.

Morris, C.J. 1971 Elcctroencephalographic and cvoked potential correlates of reaction time and visual discrimination performance. Psychonomic Science, 23, 193-195.

Nickcrson, R.S. 1973 Intersensory facilitation of reaction time: Energy summation or prepardtion enlancement? Psychological Revicw, 80, 489-509.

Nicmi, P., \& Näätanen, R. 1981 lorepcriod and simple reaction lime. Pyychological Bulletin, 89, 133-162.

Nissen, M.J. 1977 Stintulus intensity and information proccssing. Perceplion $\&$ Psychophysics, 22, $338-352$.

l'arker, D. M., \& Salzen, E. A. 1982 Lvoked potentials and reaction times to the ofliset and contrast reversal of sinusoidal gratings. Vision Re search, 22, 205-207.

Teichner, W. H. 1954 Recent studies of simple reaction time. Psychological Bulletin, 51, 128-149.

Vaughan, H. G., Costa, L. D., \& Gilden, L. 1966 The functional relation of visual cvokcd responsc and reaction time to stimulus intensity. Vision Rescardh, 6, 645-656.

(Received Scpt. 25, 1984; accepted Nov. 9, 1985) 